OPEN ACCESS

Edited by:

Ying Zhang,

Johns Hopkins University, USA

Reviewed by:

Magilé De La Caridad Fonseca, Institute of Tropical Medicine 'Pedro Kouri', Cuba

Onya Opota,

Lausanne University Hospital,

Switzerland

*Correspondence:

Takashi Shimizu

shimizut@yamaguchi-u.ac.jp

Specialty section: This article was submitted to

Infectious Diseases,

a section of the journal

Frontiers in Microbiology

Received: 02 February 2015 Accepted: 14 March 2016

Published: 31 March 2016

Citation:

Shimizu T (2016) Inflammation-inducing Factors of Mycoplasma pneumoniae.

Front. Microbiol. 7:414. doi: 10.3389/fmicb.2016.00414

\section{Inflammation-inducing Factors of Mycoplasma pneumoniae}

\author{
Takashi Shimizu* \\ Laboratory of Veterinary Public Health, Joint Faculty of Veterinary Medicine, Yamaguchi University, Yamaguchi, Japan
}

Mycoplasma pneumoniae, which causes mycoplasmal pneumonia in human, mainly causes pneumonia in children, although it occasionally causes disease in infants and geriatrics. Some pathogenic factors produced by $M$. pneumoniae, such as hydrogen peroxide and Community-Acquired Respiratory Distress Syndrome (CARDS) toxin have been well studied. However, these factors alone cannot explain this predilection. The low incidence rate of mycoplasmal pneumonia in infants and geriatrics implies that the strong inflammatory responses induced by $M$. pneumoniae coordinate with the pathogenic factors to induce pneumonia. However, $M$. pneumoniae lacks a cell wall and does not possess an inflammation-inducing endotoxin, such as lipopolysaccharide (LPS). In M. pneumoniae, lipoproteins were identified as an inflammation-inducing factor. Lipoproteins induce inflammatory responses through Toll-like receptors (TLR) 2. Because Mycoplasma species lack a cell wall and lipoproteins anchored in the membrane are exposed, lipoproteins and TLR2 have been thought to be important for the pathogenesis of $M$. pneumoniae. However, recent reports suggest that $M$. pneumoniae also induces inflammatory responses also in a TLR2-independent manner. TLR4 and autophagy are involved in this TLR2-independent inflammation. In addition, the CARDS toxin or $M$. pneumoniae cytadherence induces inflammatory responses through an intracellular receptor protein complex called the inflammasome. In this review, the inflammation-inducing factors of $M$. pneumoniae are summarized.

Keywords: mycoplasma, lipoprotein, cytadherence, inflammation, pneumonia

\section{INTRODUCTION}

Mycoplasma pneumoniae causes primary atypical pneumonia, tracheobronchitis, pharyngitis, and asthma in humans (Gil et al., 1993; Kraft et al., 1998; Waites and Talkington, 2004). The age distribution of patients with pneumonia caused by $M$. pneumoniae is characteristic. The incidence is highest among school-aged children and young adults and lower in infants and geriatrics (Denny et al., 1971; Foy et al., 1979). Some pathogenic factors of M. pneumoniae, such as hydrogen peroxide, Community-Acquired Respiratory Distress Syndrome (CARDS) toxin, and nuclease, have been reported to be associated with the development of pneumonia (Somerson et al., 1965; Cohen and Somerson, 1967; Kannan and Baseman, 2006; Hames et al., 2009; Somarajan et al., 2010). However, these pathogenic factors are insufficient to explain the age distribution of patients with pneumonia caused by M. pneumoniae. Generally, the immune system in infants and geriatrics is immature compared with that in young adults. The symptoms of pneumonia caused by M. pneumoniae are correlated with the induction of pro-inflammatory cytokines (Tryon and Baseman, 1992; Salvatore et al., 2007). These findings suggest that the excessive immune responses 
induced by $M$. pneumoniae play an important role in the development of pneumonia. In this review, the molecular mechanisms of inflammation induced by $M$. pneumoniae are summarized (Table 1).

\section{LIPOPROTEINS AND TOLL-LIKE RECEPTORS (TLRs)}

\section{Lipoproteins of Mycoplasma Species}

It has been reported that some Mycoplasma species induce pro-inflammatory cytokines and stimulate various immune cells (Atkin et al., 1986; Kirchner et al., 1986; Teh et al., 1988). Because Mycoplasma species are devoid of a cell wall and lack immune cell stimulator such as lipopolysaccharide (LPS) or peptidoglycan (Mizel et al., 1978; Staber et al., 1978), the factors responsible for the induction of inflammatory responses have been unclear for a long time. The first report on the inflammation-inducing factor of Mycoplasma species was published by Quentmeier et al. (1990). They reported that a high-molecular-weight (HMW) protein of M. fermentans known as MDHM possesses interleukin (IL)-6-inducing activity in macrophages. Because the activity of MDHM was resistant to proteinase $\mathrm{K}$, the active component of MDHM was thought to be a low-molecular-weight compound. In 1996, Muhlradt et al. identified the active component of MDHM as S-(2,3-dihydroxypropyl) cysteine (Muhlradt et al., 1996). This component was similar to the $\mathrm{N}$-terminal structure of an Escherichia coli-derived lipoprotein identified in 1969 by Braun et al. Braun (1975). Muhlradt et al. (1997) also purified the inflammation-inducing factor from M. fermentans culture and demonstrated that the active component is the diacylated lipopeptide, $S$-(2,3-bisacyloxypropyl)CGNNDESNISFKEK. They named it macrophage-activating

TABLE 1 | Summary of the inflammation-inducing factors of Mycoplasma pneumoniae.

\begin{tabular}{lll}
\hline Gene ID & Original function & Function in inflammation \\
\hline MPN602 & Fo F 1 ATP synthase subunit b & Diacylated lipoprotein \\
MPN052 & & \\
MPN162 & Hypothetical & Triacylated lipoprotein \\
MPN415 & & \\
MPN611 & & \\
MPN141 & Cytadherence, P1 adhesin & Pro-inflammatory cytokine \\
& & induction \\
MPN142 & Cytadherence, P40, P90 & \\
MPN453 & Cytadherence, P30 & \\
MPN447 & Cytadherence, HMW1 & Activation of inflammasome \\
MPN372 & ADP-ribosylating toxin, & \\
& CARDS toxin & \\
MPN333 & ABC transporter & Autophagy/TLR4 dependent \\
MPN597 & Fo F ATP synthase subunit $\varepsilon$ & inflammation
\end{tabular}

lipopeptide-2 (MALP-2). After these reports, inflammationinducing lipoproteins were purified and identified in various Mycoplasma species (Jan et al., 1996a; Muhlradt et al., 1997, 1998; Shibata et al., 2000), including M. pneumoniae (Shimizu et al., 2005).

\section{Structure of Lipoprotein and TLR}

Lipoproteins were discovered in 1969 by Braun et al. (Braun, 1975). Lipoproteins are hydrophilic membrane proteins characterized by a conserved $\mathrm{N}$-terminal lipid-modified cysteine residue. Lipoproteins contain $S$-glyceryl cysteine modified with three fatty acids ( $N$-acyl-S-diacylglyceryl cysteine) at their N-terminal. This triacylated structure is also called Braun's lipoprotein. Braun's Lipoproteins are synthesized by the following three steps (Figure 1): (1) Transfer of the diacylglyceryl moiety from a membrane phospholipid to a cysteine residue of a protein through the recognition of the lipobox (L-[A/S/T]-[G/A]-C) by prolipoprotein diacylglyceryl transferase (Lgt); (2) Digestion of the signal sequence at the amino-terminal side of the cysteine by prolipoprotein signal peptidase (Lsp); and (3) Linkage of an acyl chain to the amino group of the amino-terminal cysteine ( $N$-acylation) by prolipoprotein $\mathrm{N}$-acyl-transferase (Lnt). Because genes orthologous to Lnt gene are not found in some bacterial species (Firmicutes and and Tenericutes), including Mycoplasma species, lipoproteins from these bacterial species have been assumed to be of the diacylated form (Nakayama et al., 2012).

Toll-like receptors are a type of pattern-recognition receptors that play critical roles in early innate recognition and host inflammatory responses against invading microbes (Kopp and Medzhitov, 1999; Akira and Takeda, 2004). Among the 11 reported TLR family members, TLR2 plays a central role in the recognition of lipoproteins. TLR2 recognizes the $S$-diacylglyceryl cysteine portions of both diacylated and triacylated lipoproteins (Botos et al., 2011). TLR1 coordinate with TLR2 to recognize triacylated lipoproteins through the recognition of the third acyl chain amide-linked to the cysteine using a hydrophobic pocket within TLR1 (Jin et al., 2007). However, TLR2 alone is not able to recognize diacylated lipoproteins. TLR6 assists in the recognition of diacylated lipoproteins by associating with the amino acid portion of diacylated lipoproteins (Kang et al., 2009). Although there are some exceptions (Buwitt-Beckmann et al., 2005; Kurokawa et al., 2009), diacylated and triacylated lipoproteins are generally recognaized by TLR $2 / 6$ and TLR $2 / 1$ heterodimers, respectively.

The presence of triacylated lipoproteins in Mycoplasma species has been controversial. The lipoproteins from M. fermentans, M. hyorhinis, M. salivarium, and M. gallisepticum have been shown to be diacylated lipoproteins and not $N$-acylated (Jan et al., 1996a; Muhlradt et al., 1997, 1998; Shibata et al., 2000). The Lnt gene, which encodes the enzyme responsible for $\mathrm{N}$-acylation has not been found in any mycoplasma genomes (Fraser et al., 1995; Himmelreich et al., 1996; Sasaki et al., 2002). However, a study on the ratio of $\mathrm{N}$-amide and $\mathrm{O}$-ester bonds in M. gallisepticum and M. mycoides suggested the presence of triacylated lipoproteins (Jan et al., 1996b). Furthermore, the 


\section{$\mathrm{SH}_{2}$
$\mathrm{H}_{2} \mathrm{~N}-\mathrm{XXL}(\mathrm{A} / \mathrm{S} / \mathrm{T})(\mathrm{G} / \mathrm{A}) \mathrm{C} X X X X X X X X-\mathrm{COOH}$}

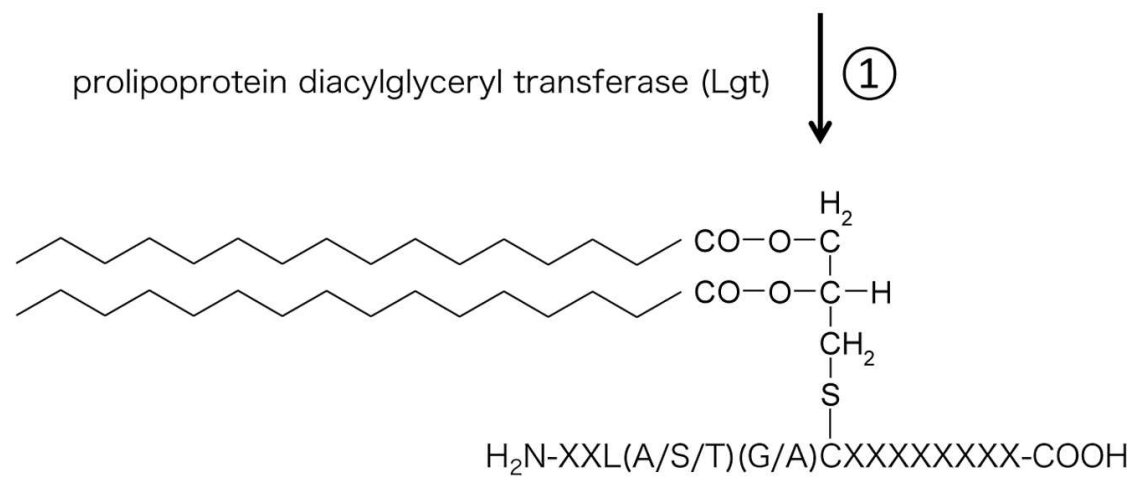

prolipoprotein signal peptidase (Lsp) $\downarrow$ (2)

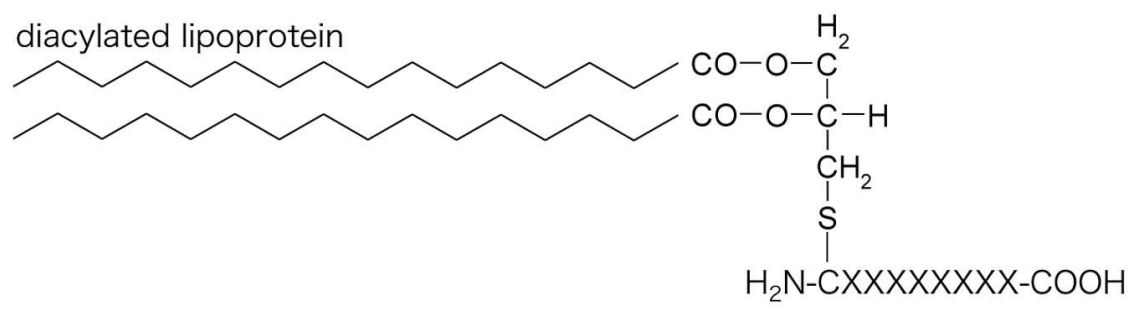

prolipoprotein $N$-acyl-transferase (Lnt) $\downarrow$ (3)

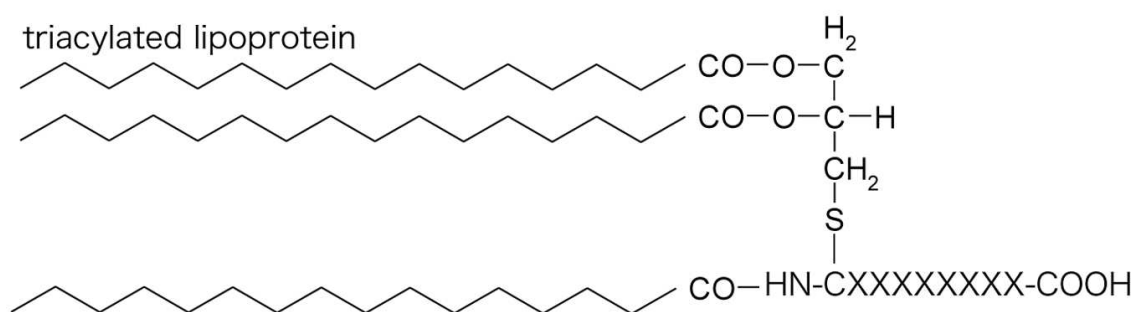

FIGURE 1 | Biosynthesis of bacterial lipoproteins. (1) Lgt transfers a diacylglyceryl moiety from a phospholipid to the sulfhydryl group of the cysteine located after the lipobox sequence. (2) Lsp cleaves the signal peptide at the N-terminus of the cysteine. (3) Lnt transfers an acyl chain derived from phospholipid to the amino group of the cysteine.

resistance to Edoman degradation of proteins from $M$. mycoides also indicated the presence of $N$-acylation (Chambaud et al., 1999). These data imply the presence of triacylated lipoproteins in Mycoplasma species.

\section{Lipoproteins of M. pneumoniae}

Lipoproteins of $M$. pneumonie are summarized in Table 2. In M. pneumoniae, Shimizu et al. (2005) reported that the subunit $b$ of the $\mathrm{F}_{0} \mathrm{~F}_{1}$ ATP synthase (MPN602) is a diacylated lipoprotein that induces inflammatory responses through TLR2. Into et al. (2007) also reported that M. pneumoniae has 48 lipoproteins and that the common N-terminal structure of these lipoproteins induces inflammatory responses. Interestingly, Some of these lipoproteins (MPN162, MPN611) were recognized by TLR1 and TLR2, suggesting that M. pneumoniae contains triacylted lipoproteins (Shimizu et al., 2007). Kurokawa et al. 


\begin{tabular}{|c|c|c|c|c|}
\hline Gene ID & $\begin{array}{l}\text { Gene } \\
\text { symbol }\end{array}$ & Original function & $\begin{array}{l}\text { Usage } \\
\text { of TLR }\end{array}$ & $\begin{array}{l}\text { Number of } \\
\text { acyl chain }\end{array}$ \\
\hline MPN011 & & Hypothetical & & \\
\hline MPN052 & & Hypothetical & & $3^{a}$ \\
\hline MPN054 & & Hypothetical & & \\
\hline MPN058 & & Hypothetical & & \\
\hline MPN083 & & Hypothetical & & \\
\hline MPN097 & & Pseudo & & \\
\hline MPN133 & & Hypothetical & & \\
\hline MPN152 & & Hypothetical & & \\
\hline MPN162 & & Hypothetical & 1,2 & $3^{b}$ \\
\hline MPN199 & & Hypothetical & & \\
\hline MPN200 & & Hypothetical & & \\
\hline MPN271 & & Hypothetical & & \\
\hline MPN281 & & Pseudo & & \\
\hline MPN284 & & Hypothetical & & \\
\hline MPN288 & & Hypothetical & & \\
\hline MPN363 & & Hypothetical & & \\
\hline MPN369 & & Hypothetical & & \\
\hline MPN408 & & Hypothetical & & \\
\hline MPN411 & & Hypothetical & & \\
\hline MPN415 & & $\begin{array}{l}\text { High affinity transport system } \\
\text { protein P37 }\end{array}$ & & $3^{a}$ \\
\hline MPN436 & & Hypothetical & & \\
\hline MPN439 & & Pseudo & & \\
\hline MPN442 & & Hypothetical & & \\
\hline MPN456 & & Hypothetical & & \\
\hline MPN459 & & Hypothetical & & \\
\hline MPN467 & & Hypothetical & & \\
\hline MPN489 & & Hypothetical & & \\
\hline MPN506 & & Hypothetical & & \\
\hline MPN523 & & Hypothetical & & \\
\hline MPN582 & & Hypothetical & & \\
\hline MPN585 & & Hypothetical & & \\
\hline MPN587 & & Hypothetical & & \\
\hline MPN588 & & Hypothetical & & \\
\hline MPN590 & & Hypothetical & & \\
\hline MPN592 & & Hypothetical & & \\
\hline MPN602 & atpF & $\mathrm{F}_{0} \mathrm{~F}_{1}$ ATP synthase subunit $\mathrm{b}$ & 2,6 & $2^{b}$ \\
\hline MPN611 & & $\begin{array}{l}\text { Phosphate } \mathrm{ABC} \text { transporter } \\
\text { substrate-binding protein }\end{array}$ & 1,2 & $3^{b}$ \\
\hline MPN639 & & Hypothetical & & \\
\hline MPN640 & & Hypothetical & & \\
\hline MPN641 & & Hypothetical & & \\
\hline MPN642 & & Hypothetical & & \\
\hline MPN643 & & Hypothetical & & \\
\hline MPN644 & & Hypothetical & & \\
\hline MPN645 & & Hypothetical & & \\
\hline MPN646 & & Hypothetical & & \\
\hline MPN647 & & Hypothetical & & \\
\hline MPN650 & & Hypothetical & & \\
\hline MPN654 & & Hypothetical & & \\
\hline
\end{tabular}

${ }^{a}$ Determined by lipase-based mass spectrometry analysis.

${ }^{\mathrm{b}}$ Estimated from TLR usage.
(2012) analyzed the detailed structure of M. pneumoniae lipoproteins using lipoprotein lipase-based mass spectrometry analysis, and demonstrated that some of $M$. pneumoniae lipoproteins (MPN052, MPN415) are triacylated. In this study, triacylated lipoproteins were also found in M. genitalium. These findings led to the conclusion that Mycoplasma species possess triacylated lipoproteins and indicated that a new enzyme with Lnt activity exists in Mycoplasma species. Although the modification of other 43 lipoproteins of $M$. penoumoniae is still unclear, the lipoproteins of $M$. pneumoniae seem mixture of diacylated and triacylated lipoproteins. Induction of inflammatory responses through both TLR2/6 and TLR2/1 by diacylated and triacylated lipoproteins may affect the strong inflammation in $M$. pneumoniae infection.

\section{TLR2-INDEPENDENT INFLAMMATION}

\section{M. pneumoniae and Autophagy}

Because Mycoplasma species lack cell walls, they do not contain immunostimulants such as LPS, peptidoglycan, or lipoteichoic acid. Therefore, lipoproteins seem to be key factors in $M$. pneumoniae-induced inflammatory responses and to facilitate the development of pneumonia in humans. However, the existence of lipoproteins in non-pathogenic Mycoplasma species suggests the presence of an alternative mechanism by which $M$. pneumoniae induce inflammatory responses.

Autophagy is a cellular response that involves the sequestration of regions within the cytosol with double membrane compartments. Autophagy has been shown to play important roles in the cellular response to starvation, cell death, removal of damaged organelles, and neurodegenerative diseases (Levine, 2005). It has recently been recognized that autophagy is involved in both innate and adaptive immunity against various microorganisms (Schmid and Munz, 2007; Deretic et al., 2013; Ma et al., 2013).

Recently, Shimizu et al. demonstrated that M. pneumoniae induces strong inflammatory responses, even in macrophages derived from TLR2 knockout (KO) mice (Shimizu et al., 2014). M. pneumoniae internalized into macrophages through phagocytosis were co-localized with the autophagosome, and autophagy inhibitors decreased the induction of proinflammatory cytokines, suggesting the autophagy-mediated induction of inflammatory responses. Because this TLR2independent induction was inhibited in macrophages derived from TLR2/4 double KO mouse, TLR4 is also involved. In this study, they also reported that the ABC-transporter (MPN333), and $\mathrm{F}_{0} \mathrm{~F}_{1}$ ATP synthase subunit $\varepsilon$ (MPN597) of M. pneumoniae are essential for the activation of the autophagy/TLR4-mediated pathway.

\section{M. pneumoniae and the Inflammasome}

Inflammasomes are intracellular receptors (Martinon et al., 2009), that respond to various signals, including intracellular bacterial toxins, pathogen-associated molecular patterns 


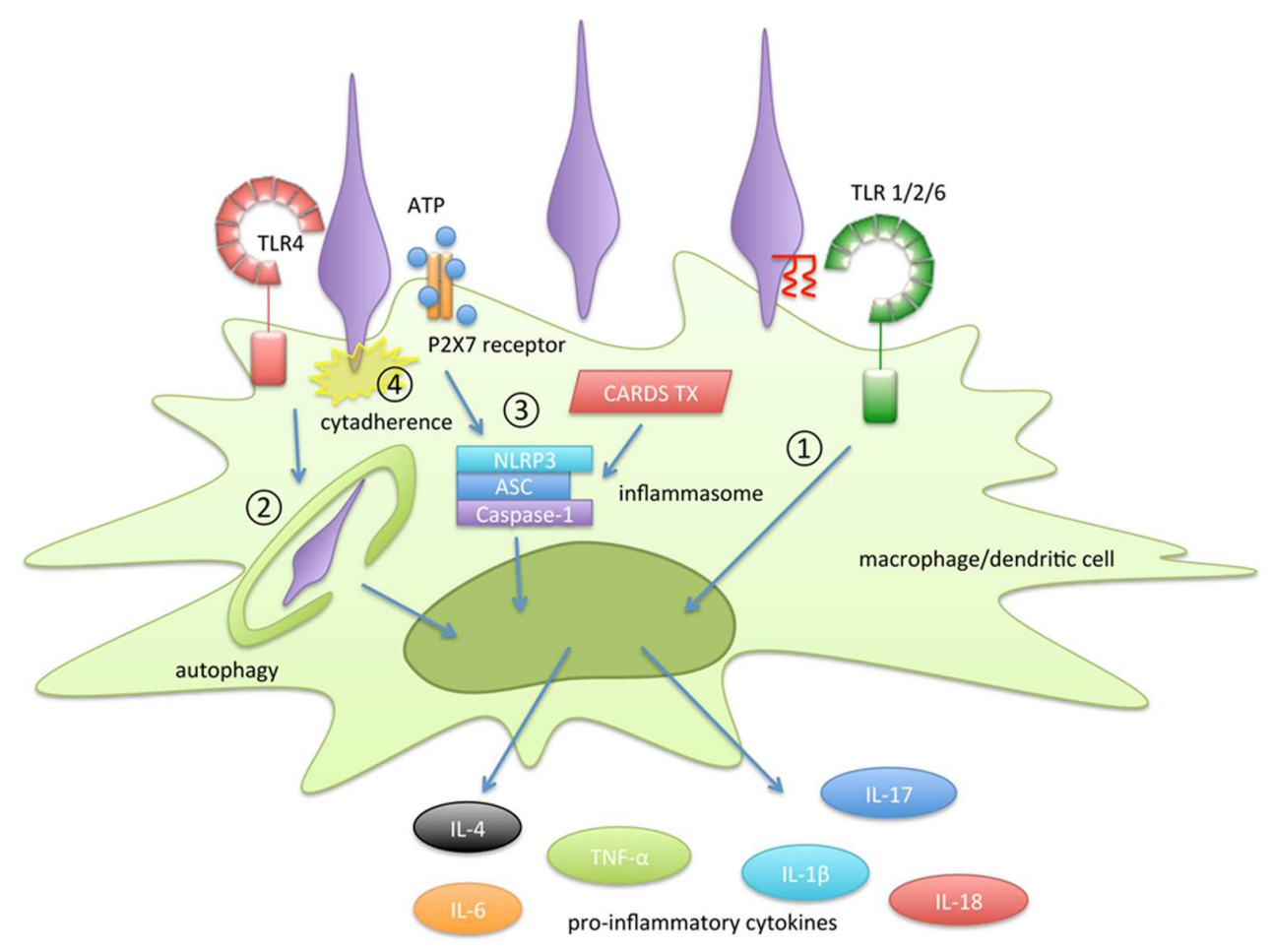

FIGURE 2 | Summary of the inflammation-inducing pathways in Mycoplasma pneumoniae infection. The following four pathways are involved in the induction of inflammatory responses: (1) recognition of lipoprotein by TLR2, (2) autophagy-mediated signaling, (3) activation of inflammasomes, and (4) cytadherence property.

(PAMPs) (Martinon et al., 2004; Miao et al., 2007), damageassociated molecular patterns (DAMPs) (Kanneganti et al., 2006; Mariathasan et al., 2006; Sutterwala et al., 2006), and reactive oxygen species (Dostert et al., 2008; Allen et al., 2009). Activated inflammasomes cleave the precursors of pro-inflammatory cytokines, such as IL-1 $\beta$ and IL-18 through caspase- 1 or caspase-11, and release them (Boyden and Dietrich, 2006).

Shimizu et al. (2011) reported that M. pneumoniae induces efflux of ATP from host cells. The efflux of ATP activated inflammasomes via the $\mathrm{P} 2 \mathrm{X} 7$ receptor, which is followed by the secretion of IL-1 $\beta$. A recent report by Sugiyama et al. (2015) also demonstrated that $M$. pnumoniae induces IL- $1 \beta$ through the NLRP3 inflammasome in a dendritic cell line.

Interestingly, Bose et al. (2014) showed that CARDS toxin (MPN372) regulates NLRP3 inflammasome activity. CARDs toxin is a vacuolating cytotoxin produced by some Mycoplasma species, including M. pneumoniae. Its C-terminal region is responsible for its vacuolating activity (Kannan and Baseman, 2006; Kannan et al., 2014). Its N-terminal region shares sequence similarity with pertussis toxin and is essential for its ADP-ribosylating activity. In this study, they demonstrated that CARDS toxin activates inflammasomes through the ADP-ribosylation of NLRP3 and enhances the secretion of IL-1 $\beta$.

Taken together, these findings suggest that inflammasomes play an important role in the inflammation induced by M. pneumoniae.

\section{Cytadherence of M. pneumoniae and Inflammation}

Cytadherence property is one of the unique characteristics of $M$. pneumoniae. Cytadherence in the respiratory tract, the initial event in $M$. pneumoniae infection, is mediated by P1 (MPN141) adhesin and other accessory proteins, such as P30 and HMW proteins (Krause and Balish, 2001; Balish and Krause, 2002; Miyata, 2008a,b). The relationship between cytoadherence and the induction of inflammatory responses was first reported in Yang et al. (2002). They demonstrated that protease treatment or anti-P1 antibody treatment decreases the induction of pro-inflammatory cytokines, including IL-1 $\beta$. Hoek et al. (2005) reported that culturing M. pneumoniae in polypropylene bottles reduces the expression of P1 adhesin. Under these conditions, the induction of IL-4 from mast cells was significantly decreased. As described above, Shimizu et al. reported that $M$. pneumoniae induces the efflux of ATP from host cells, followed by the activation of inflammasomes and secretion of IL-1 $\beta$. In this study, they also reported that cytadherence-deficient mutants lacking P90 and P40 (MPN142, $130 \mathrm{kDa}$ precursor) or HMW1 and P30 (MPN447 and MPN453, respectively) fail to induce IL-1 $\beta$ through ATP efflux. Cytadherence was also associated with autophagy/TLR4mediated induction of inflammatory responses. Mutation in ABC-transporter (MPN333), and $\mathrm{F}_{0} \mathrm{~F}_{1}$ ATP synthase subunit $\varepsilon$ (MPN597) failed to induce inflammatory responses, and these 
mutants showed a deficiency in cytadherence (Shimizu et al., 2014). Taken together, these findings indicate that cytadherence of $M$. pneumoniae is strongly associated with the induction of inflammatory responses.

\section{CONCLUSION}

In this review, the molecular mechanisms of inflammatory responses induced by $M$. pneumoniae were reviewed (Figure 2). The following four pathways are important for the induction of inflammatory responses in $M$. pneumoniae infection: 1) recognition of lipoprotein by TLR2, 2) autophagy-mediated signaling; 3) activation of inflammasomes, and 4) cytadherence property. Lipoproteins, which were the first immunostimulants discovered in Mycoplasma species, have been well studied. However, the structures of the lipoproteins in Mycoplasma species are identical to those of lipoproteins from other bacteria, including normal microflora. Therefore, lipoproteins alone are insufficient to explain the inflammatory responses induced by $M$. pneumoniae. M. pneumoniae also has the ability to induce inflammatory responses through a TLR2independent pathway. Autophagy and TLR4 are involved in this induction. Some pro-inflammatory cytokines, such as IL-1 $\beta$ and IL-18, are matured and released through inflammasome activation. Inflammasome activation is necessary to release these cytokines during $M$. pneumoniae infection. It is noteworthy that CARDS toxin enhances inflammasome activation. The distribution of CARDS toxin in Mycoplasma

\section{REFERENCES}

Akira, S., and Takeda, K. (2004). Toll-like receptor signaling. Nat. Rev. Immunol. 4, 499-511. doi: 10.1038/nri1391

Allen, I. C., Scull, M. A., Moore, C. B., Holl, E. K., McElvania-TeKippe, E., Taxman, D. J., et al. (2009). The NLRP3 inflammasome mediates in vivo innate immunity to influenza A virus through recognition of viral RNA. Immunity 30, 556-565. doi: 10.1016/j.immuni.2009.02.005

Atkin, C. L., Cole, B. C., Sullivan, G. J., Washburn, L. R., and Wiley, B. B. (1986). Stimulation of mouse lymphocytes by a mitogen derived from Mycoplasma arthritidis. V. A small basic protein from culture supernatants is a potent $\mathrm{T}$ cell mitogen. J. Immunol. 137, 1581-1589.

Balish, M. F., and Krause, D. C. (2002). "Cytadherence and the cytoskelton," in Molecular Biology and Pathogenicity of Mycoplasmas, eds S. Razin and R. Herrmann (New York, NY: Kluwer Academic), 491-518.

Bose, S., Segovia, J. A., Somarajan, S. R., Chang, T. H., Kannan, T. R., and Baseman, J. B. (2014). ADP-ribosylation of NLRP3 by Mycoplasma pneumoniae CARDS toxin regulates inflammasome activity. MBio 5:e02186. doi: $10.1128 / \mathrm{mBio} .02186-14$

Botos, I., Segal, D. M., and Davies, D. R. (2011). The structural biology of Toll-like receptors. Structure 19, 447-459. doi: 10.1016/j.str.2011.02.004

Boyden, E. D., and Dietrich, W. F. (2006). Nalp1b controls mouse macrophage susceptibility to anthrax lethal toxin. Nat. Genet. 38, 240-244. doi: $10.1038 / \mathrm{ng} 1724$

Braun, V. (1975). Covalent lipoprotein from the outer membrane of Escherichia coli. Biochim. Biophys. Acta 415, 335-377. doi: 10.1016/0304-4157(75) 90013-1

Buwitt-Beckmann, U., Heine, H., Wiesmuller, K. H., Jung, G., Brock, R., Akira, S., et al. (2005). Toll-like receptor 6-independent signaling by diacylated lipopeptides. Eur. J. Immunol. 35, 282-289. doi: 10.1002/eji.200424955 species is limited to a small number of Mycoplasma species. In addition, cytadherent property of $M$. pneumoniae is strongly associated with the autophagy/TLR4- and inflammasomemediated induction of inflammatory responses. Although some Mycoplasma species, such as $M$. genitalium and $M$. gallisepticum, have partially similar adhesin, cytadherence mediated by $\mathrm{P} 1$ adhesin is unique in M. pneumoniae. These characteristics may contribute to the greater ability of $M$. pneumoniae to induce inflammatory responses than nonpathogenic Mycoplasma species.

In addition to inflammation-inducing factors, $M$. pneumoniae shows cytotoxicity through CARDS toxin, nuclease, and hydrogen peroxide produced during glycerol metabolism. The symptoms of mycoplasmal pneumonia, such as fever and severe cough, are thought to appear as a result of a combination of inflammation and cytotoxicity induced by $M$. pneumoniae. Mycoplasmal pneumonia is still an important issue in the field of pediatric medicine. Although measures to prevent mycoplasmal pneumonia are desired worldwide, preventive measures, including vaccines, have not been developed. Therefore, the inflammation-inducing factors of M. pneumoniae described here may be suitable targets for the development of new preventive measures.

\section{AUTHOR CONTRIBUTIONS}

The author confirms being the sole contributor of this work and approved it for publication.

Chambaud, I., Wroblewski, H., and Blanchard, A. (1999). Interactions between mycoplasma lipoproteins and the host immune system. Trends Microbiol. 7, 493-499. doi: 10.1016/S0966-842X(99)01641-8

Cohen, G., and Somerson, N. L. (1967). Mycoplasma pneumoniae: hydrogen peroxide secretion and its possible role in virulence. Ann. N. Y. Acad. Sci. 143, 85-87. doi: 10.1111/j.1749-6632.1967.tb27648.x

Denny, F. W., Clyde, W. A. Jr., and Glezen, W. P. (1971). Mycoplasma pneumoniae disease: clinical spectrum, pathophysiology, epidemiology, and control. J. Infect. Dis. 123, 74-92. doi: 10.1093/infdis/123.1.74

Deretic, V., Saitoh, T., and Akira, S. (2013). Autophagy in infection, inflammation and immunity. Nat. Rev. Immunol. 13, 722-737. doi: 10.1038/nri3532

Dostert, C., Petrilli, V., Van Bruggen, R., Steele, C., Mossman, B. T., and Tschopp, J. (2008). Innate immune activation through Nalp3 inflammasome sensing of asbestos and silica. Science 320, 674-677. doi: 10.1126/science. 1156995

Foy, H. M., Kenny, G. E., Cooney, M. K., and Allan, I. D. (1979). Long-term epidemiology of infections with Mycoplasma pneumoniae. J. Infect. Dis. 139, 681-687. doi: 10.1093/infdis/139.6.681

Fraser, C. M., Gocayne, J. D., White, O., Adams, M. D., Clayton, R. A., Fleischmann, R. D., et al. (1995). The minimal gene complement of Mycoplasma genitalium. Science 270, 397-403. doi: 10.1126/science.270.5235.397

Gil, J. C., Cedillo, R. L., Mayagoitia, B. G., and Paz, M. D. (1993). Isolation of Mycoplasma pneumoniae from asthmatic patients. Ann. Allergy 70, 23-25.

Hames, C., Halbedel, S., Hoppert, M., Frey, J., and Stulke, J. (2009). Glycerol metabolism is important for cytotoxicity of Mycoplasma pneumoniae. J. Bacteriol. 191, 747-753. doi: 10.1128/JB.01103-08

Himmelreich, R., Hilbert, H., Plagens, H., Pirkl, E., Li, B. C., and Herrmann, R. (1996). Complete sequence analysis of the genome of the bacterium Mycoplasma pneumoniae. Nucleic Acids Res. 24, 4420-4449. doi: $10.1093 / \mathrm{nar} / 24.22 .4420$ 
Hoek, K. L., Duffy, L. B., Cassell, G. H., Dai, Y., and Atkinson, T. P. (2005). A role for the Mycoplasma pneumoniae adhesin P1 in interleukin (IL)-4 synthesis and release from rodent mast cells. Microb. Pathog. 39, 149-158. doi: 10.1016/j.micpath.2005.07.004

Into, T., Dohkan, J., Inomata, M., Nakashima, M., Shibata, K., and Matsushita, K. (2007). Synthesis and characterization of a dipalmitoylated lipopeptide derived from paralogous lipoproteins of Mycoplasma pneumoniae. Infect. Immunol. 75, 2253-2259. doi: 10.1128/IAI.00141-07

Jan, G., Brenner, C., and Wroblewski, H. (1996a). Purification of Mycoplasma gallisepticum membrane proteins p52, p67 (pMGA), and p77 by highperformance liquid chromatography. Protein Expr. Purif. 7, 160-166. doi: 10.1006/prep.1996.0023

Jan, G., Fontenelle, C., Verrier, F., Le Henaff, M., and Wroblewski, H. (1996b). Selective acylation of plasma membrane proteins of Mycoplasma mycoides subsp. mycoides SC, the contagious bovine pleuropneumonia agent. Curr. Microbiol. 32, 38-42. doi: 10.1007/s002849900007

Jin, M. S., Kim, S. E., Heo, J. Y., Lee, M. E., Kim, H. M., Paik, S. G., et al. (2007). Crystal structure of the TLR1-TLR2 heterodimer induced by binding of a tri-acylated lipopeptide. Cell 130, 1071-1082. doi: 10.1016/j.cell.2007.09.008

Kang, J. Y., Nan, X., Jin, M. S., Youn, S. J., Ryu, Y. H., Mah, S., et al. (2009). Recognition of lipopeptide patterns by Toll-like receptor 2-Toll-like receptor 6 heterodimer. Immunity 31, 873-884. doi: 10.1016/j.immuni.2009.09.018

Kannan, T. R., and Baseman, J. B. (2006). ADP-ribosylating and vacuolating cytotoxin of Mycoplasma pneumoniae represents unique virulence determinant among bacterial pathogens. Proc. Natl. Acad. Sci. U.S.A. 103, 6724-6729. doi: 10.1073/pnas.0510644103

Kannan, T. R., Krishnan, M., Ramasamy, K., Becker, A., Pakhomova, O. N., Hart, P. J., et al. (2014). Functional mapping of community-acquired respiratory distress syndrome (CARDS) toxin of Mycoplasma pneumoniae defines regions with ADP-ribosyltransferase, vacuolating and receptor-binding activities. Mol. Microbiol. 93, 568-581. doi: 10.1111/mmi.12680

Kanneganti, T. D., Ozoren, N., Body-Malapel, M., Amer, A., Park, J. H., Franchi, L., et al. (2006). Bacterial RNA and small antiviral compounds activate caspase-1 through cryopyrin/Nalp3. Nature 440, 233-236. doi: 10.1038/ nature04517

Kirchner, H., Bauer, A., Moritz, T., and Herbst, F. (1986). Lymphocyte activation and induction of interferon gamma in human leucocyte cultures by the mitogen in Mycoplasma arthritidis supernatant (MAS). Scand. J. Immunol. 24, 609-613. doi: 10.1111/j.1365-3083.1986.tb02177.x

Kopp, E. B., and Medzhitov, R. (1999). The Toll-receptor family and control of innate immunity. Curr. Opin. Immunol. 11, 13-18. doi: 10.1016/S09527915(99)80003-X

Kraft, M., Cassell, G. H., Henson, J. E., Watson, H., Williamson, J., Marmion, B. P., et al. (1998). Detection of Mycoplasma pneumoniae in the airways of adults with chronic asthma. Am. J. Respir. Crit. Care Med. 158, 998-1001. doi: 10.1164/ajrccm.158.3.9711092

Krause, D. C., and Balish, M. F. (2001). Structure, function, and assembly of the terminal organelle of Mycoplasma pneumoniae. FEMS Microbiol. Lett. 198, 1-7. doi: 10.1111/j.1574-6968.2001.tb10610.x

Kurokawa, K., Lee, H., Roh, K. B., Asanuma, M., Kim, Y. S., Nakayama, H., et al. (2009). The Triacylated ATP binding cluster transporter substratebinding lipoprotein of Staphylococcus aureus functions as a native ligand for Toll-like Receptor 2. J. Biol. Chem. 284, 8406-8411. doi: 10.1074/jbc.M809 618200

Kurokawa, K., Ryu, K. H., Ichikawa, R., Masuda, A., Kim, M. S., Lee, H., et al. (2012). Novel bacterial lipoprotein structures conserved in low-GC content gram-positive bacteria are recognized by Toll-like receptor 2. J. Biol. Chem. 287, 13170-13181. doi: 10.1074/jbc.M111.292235

Levine, B. (2005). Eating oneself and uninvited guests: autophagy-related pathways in cellular defense. Cell 120, 159-162. doi: 10.1016/j.cell.2005.01.005

Ma, Y., Galluzzi, L., Zitvogel, L., and Kroemer, G. (2013). Autophagy and cellular immune responses. Immunity 39, 211-227. doi: 10.1016/j.immuni.2013.07.017

Mariathasan, S., Weiss, D. S., Newton, K., McBride, J., O’Rourke, K., Roose-Girma, M., et al. (2006). Cryopyrin activates the inflammasome in response to toxins and ATP. Nature 440, 228-232. doi: 10.1038/ nature 04515

Martinon, F., Agostini, L., Meylan, E., and Tschopp, J. (2004). Identification of bacterial muramyl dipeptide as activator of the NALP3/cryopyrin inflammasome. Curr. Biol. 14, 1929-1934. doi: 10.1016/j.cub.2004 10.027

Martinon, F., Mayor, A., and Tschopp, J. (2009). The inflammasomes: guardians of the body. Annu. Rev. Immunol. 27, 229-265. doi: 10.1146/annurev.immunol.021908.132715

Miao, E. A., Andersen-Nissen, E., Warren, S. E., and Aderem, A. (2007). TLR5 and Ipaf: dual sensors of bacterial flagellin in the innate immune system. Semin. Immunopathol. 29, 275-288. doi: 10.1007/s00281-007-0078-z

Miyata, M. (2008a). Centipede and inchworm models to explain Mycoplasma gliding. Trends Microbiol. 16, 6-12. doi: 10.1016/j.tim.2007.11.002

Miyata, M. (2008b). "Molecular mechanism of mycoplasma gliding - a novel cell motility system," in Cell Motility, ed. P. Lenz (New York, NY: Springer Science), $137-175$.

Mizel, S. B., Oppenheim, J. J., and Rosentreich, D. L. (1978). Characterization of lymphocyte-activating factor (LAF) produced by a macrophage cell line, P388D1. II. Biochemical characterization of LAF induced by activated T cells and LPS. J. Immunol. 120, 1504-1508.

Muhlradt, P. F., Kiess, M., Meyer, H., Sussmuth, R., and Jung, G. (1997). Isolation, structure elucidation, and synthesis of a macrophage stimulatory lipopeptide from Mycoplasma fermentans acting at picomolar concentration. J. Exp. Med. 185, 1951-1958. doi: 10.1084/jem.185.11.1951

Muhlradt, P. F., Kiess, M., Meyer, H., Sussmuth, R., and Jung, G. (1998). Structure and specific activity of macrophage-stimulating lipopeptides from Mycoplasma hyorhinis. Infect. Immun. 66, 4804-4810.

Muhlradt, P. F., Meyer, H., and Jansen, R. (1996). Identification of S(2,3-dihydroxypropyl)cystein in a macrophage-activating lipopeptide from Mycoplasma fermentans. Biochemistry 35, 7781-7786. doi: 10.1021/bi9602831

Nakayama, H., Kurokawa, K., and Lee, B. L. (2012). Lipoproteins in bacteria: structures and biosynthetic pathways. FEBS J. 279, 4247-4268. doi: 10.1111/febs.12041

Quentmeier, H., Schmitt, E., Kirchhoff, H., Grote, W., and Muhlradt, P. F. (1990). Mycoplasma fermentans-derived high-molecular-weight material induces interleukin-6 release in cultures of murine macrophages and human monocytes. Infect. Immun. 58, 1273-1280.

Salvatore, C. M., Fonseca-Aten, M., Katz-Gaynor, K., Gomez, A. M., Mejias, A., Somers, C., et al. (2007). Respiratory tract infection with Mycoplasma pneumoniae in interleukin-12 knockout mice results in improved bacterial clearance and reduced pulmonary inflammation. Infect. Immun. 75, 236-242. doi: 10.1128/IAI.01249-06

Sasaki, Y., Ishikawa, J., Yamashita, A., Oshima, K., Kenri, T., Furuya, K., et al. (2002). The complete genomic sequence of Mycoplasma penetrans, an intracellular bacterial pathogen in humans. Nucleic Acids Res. 30, 5293-5300. doi: $10.1093 / \mathrm{nar} / \mathrm{gkf} 667$

Schmid, D., and Munz, C. (2007). Innate and adaptive immunity through autophagy. Immunity 27, 11-21. doi: 10.1016/j.immuni.2007.07.004

Shibata, K., Hasebe, A., Into, T., Yamada, M., and Watanabe, T. (2000). The $\mathrm{N}$-terminal lipopeptide of a $44-\mathrm{kDa}$ membrane-bound lipoprotein of Mycoplasma salivarium is responsible for the expression of intercellular adhesion molecule- 1 on the cell surface of normal human gingival fibroblasts. J. Immunol. 165, 6538-6544. doi: 10.4049/jimmunol.165. 11.6538

Shimizu, T., Kida, Y., and Kuwano, K. (2005). A dipalmitoylated lipoprotein from Mycoplasma pneumoniae activates NF-kappa B through TLR1, TLR2, and TLR6. J. Immunol. 175, 4641-4646. doi: 10.4049/jimmunol.175. 7.4641

Shimizu, T., Kida, Y., and Kuwano, K. (2007). Triacylated lipoproteins derived from Mycoplasma pneumoniae activate nuclear factor-kappaB through tolllike receptors 1 and 2. Immunology 121, 473-483. doi: 10.1111/j.13652567.2007.02594.X

Shimizu, T., Kida, Y., and Kuwano, K. (2011). Cytoadherence-dependent induction of inflammatory responses by Mycoplasma pneumoniae. Immunology 133, 51-61. doi: 10.1111/j.1365-2567.2011.03408.x

Shimizu, T., Kimura, Y., Kida, Y., Kuwano, K., Tachibana, M., Hashino, M., et al. (2014). Cytadherence of Mycoplasma pneumoniae induces inflammatory responses through autophagy and toll-like receptor 4. Infect. Immun. 82, 3076-3086. doi: 10.1128/IAI.01961-14

Somarajan, S. R., Kannan, T. R., and Baseman, J. B. (2010). Mycoplasma pneumoniae Mpn133 is a cytotoxic nuclease with a glutamic acid-, lysine- and 
serine-rich region essential for binding and internalization but not enzymatic activity. Cell Microbiol. 12, 1821-1831. doi: 10.1111/j.1462-5822.2010. 01513.x

Somerson, N. L., Walls, B. E., and Chanock, R. M. (1965). Hemolysin of Mycoplasma pneumoniae: tentative identification as a peroxide. Science 150, 226-228. doi: 10.1126/science.150.3693.226

Staber, F. G., Gisler, R. H., Schumann, G., Tarcsay, L., Schlafli, E., and Dukor, P. (1978). Modulation of myelopoiesis by different bacterial cell-wall components: induction of colony-stimulating activity (by pure preparations, low-molecular-weight degradation products, and a synthetic low-molecular analog of bacterial cell-wall components) in vitro. Cell Immunol. 37, 174-187.

Sugiyama, M., Saeki, A., Hasebe, A., Kamesaki, R., Yoshida, Y., Kitagawa, Y., et al. (2015). Activation of inflammasomes in dendritic cells and macrophages by Mycoplasma salivarium. Mol. Oral Microbiol. doi: 10.1111/omi.12117 [Epub ahead of print].

Sutterwala, F. S., Ogura, Y., Szczepanik, M., Lara-Tejero, M., Lichtenberger, G. S., Grant, E. P., et al. (2006). Critical role for NALP3/CIAS1/Cryopyrin in innate and adaptive immunity through its regulation of caspase-1. Immunity 24, 317-327. doi: 10.1016/j.immuni.2006.02.004

Teh, H. S., Ho, M., and Williams, L. D. (1988). Suppression of cytotoxic responses by a supernatant factor derived from Mycoplasma hyorhinis-infected mammalian cell lines. Infect. Immun. 56, 197-203.
Tryon, V. V., and Baseman, J. B. (1992). "Pathgenic determinant and mechanisms," in Mycoplasmas- Molecular Biology and Pathogenesis, eds J. Maniloff, R. N. McElhaney, L. R. Finch, and J. B. Baseman (Washington, DC: American Society for Microbiology), 457-489.

Waites, K. B., and Talkington, D. F. (2004). Mycoplasma pneumoniae and its role as a human pathogen. Clin. Microbiol. Rev. 17, 697-728. doi: 10.1128/CMR.17.4.697-728.2004

Yang, J., Hooper, W. C., Phillips, D. J., and Talkington, D. F. (2002). Regulation of proinflammatory cytokines in human lung epithelial cells infected with Mycoplasma pneumoniae. Infect. Immun. 70, 3649-3655. doi: 10.1128/IAI.70.7.3649-3655.2002

Conflict of Interest Statement: The author declares that the research was conducted in the absence of any commercial or financial relationships that could be construed as a potential conflict of interest.

Copyright (c) 2016 Shimizu. This is an open-access article distributed under the terms of the Creative Commons Attribution License (CC BY). The use, distribution or reproduction in other forums is permitted, provided the original author(s) or licensor are credited and that the original publication in this journal is cited, in accordance with accepted academic practice. No use, distribution or reproduction is permitted which does not comply with these terms. 